\title{
Essay. A Fourth Ideology of Individualism: Adding "Online Individuality" to a Theoretical Lens
}

\author{
Todd W. Greene ${ }^{1}$
}

\begin{abstract}
Robert Putnam (2020) suggests Americans have become more individualistic every decade since the 1960's. I have suggested that individualism is not a single monolith, but rather three different ideologies of individualism that have become entangled (2008). Consequences of these individualisms include widespread selfabsorption, and a lack of desire to correct structural problems. This article adds a fourth ideology, the ideology of online individuality, to the three previously stated. The consequences of this ideology are very similar to the others. Implications of ever-increasing individualism are raised. Solutions are suggested. [Article copies available for a fee from The Transformative Studies Institute. E-mail address:_journal@transformativestudies.org Website: http://www.transformativestudies.org (C2022 by The Transformative
\end{abstract} Studies Institute. All rights reserved.]

KEYWORDS: Individualism, Ideology, Online Individuality, SelfEsteem, Self-Reliance.

\section{INTRODUCTION}

Individualism, in the USA, is comparable today to the high levels it possessed in the 1890's. Robert Putnam's graph in The Upswing (2020, p. 13) suggests that 1960 was the pinnacle of its opposite, "community spirit." Every decade since the USA has become more individualistic and less civic minded (Putnam, 2020). Persons born in the 1960's have seen trends toward individualism increase every decade they have lived. Putnam's graph resembles an inverted "V." Traveling down both sides

\footnotetext{
${ }^{1}$ Todd Greene, Ph.D., is an Assistant Professor of Criminal Justice at Waldorf University. He has been constructing innovative theories for 30 years. His book, The Discovery of Spiritual Chivalry, integrates social sciences, theology, and personal experience in new ways. In this article, Greene adds a fourth ideology of individualism to the three he delineated in 2008. Implications of a culture becoming even more individualistic are raised.
} 